P-ISSN: 2541-6960; E-ISSN: 2549-8754

Yupa: Historical Studies Journal

Vol. 5 No. 1, 2021 (33-45)

http://jurnal.fkip.unmul.ac.id/index.php/yupa

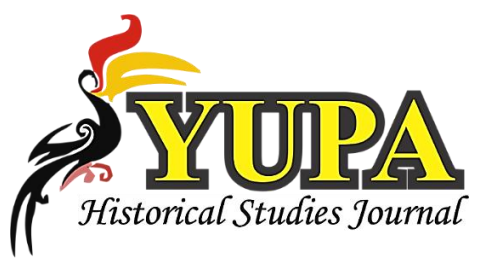

\title{
Islamisasi Kerajaan Kutai Kertanegara Abad Ke-16: Studi Historiografi Naskah Arab Melayu Salasilah Kutai
}

\author{
Muhammad Sarip ${ }^{\mathbf{1}}$, Nabila Nandini ${ }^{2}$ \\ ${ }^{1}$ MSI Kalimantan Timur, Samarinda, Indonesia \\ ${ }^{2}$ Lasaloka-KSB, Samarinda, Indonesia \\ ${ }^{1}$ msarip19@gmail.coml, ${ }^{2}$ nabiland22@gmail.com
}

\begin{tabular}{ccc}
\hline Received & Accepted & Published \\
$22 / 06 / 2021$ & $03 / 08 / 2021$ & $21 / 08 / 2021$ \\
\hline
\end{tabular}

\begin{abstract}
The event of Islamization in Kutai Kertanegara Monarchy needs to be reviewed on the basis of verified primary sources. This study aims to analyze the validity of Surat Salasilah Raja dalam Negeri Kutai Kertanegara Malay-Arabic script, as a source of traditional historiography. The script describes the process of Islamization in the Monarchy of Kutai Kertanegara whence it begins as mythological texts then written as historical narratives. With historical research methods, the main source of this research is the book of Letters of Salasilah Raja in Kutai Kertanegara in Arabic Malay script by Khatib Muhammad Thahir which was completed in 1849. The results of the study show that, with strict verification, Salasilah Kutai is a valid historical source. The process of Islamization in the Kutai Kertanegara Monarchy took place through the role of a preacher named Tuan Tunggang Parangan who carried out an egalitarian dialectic to Raja Makota, in 1575.
\end{abstract}

Keywords: Islam, Islamization, Kutai Kertanegara Monarchy, Salasilah Kutai

Abstrak Peristiwa dan proses masuknya Islam di Kerajaan Kutai Kertanegara perlu dikaji kembali berbasis sumber primer yang terverifikasi. Penelitian ini bertujuan menganalisis validitas naskah aksara Arab Melayu bernama Surat Salasilah Raja dalam Negeri Kutai Kertanegara sebagai sumber historiografi tradisional dan mendeskripsikan proses Islamisasi Kerajaan Kutai Kertanegara dari teks mitologis menjadi narasi historis. Dengan metode penelitian sejarah, sumber utama penelitian ini adalah kitab Surat Salasilah Raja dalam Negeri Kutai Kertanegara beraksara Arab Melayu karya Khatib Muhammad Thahir yang selesai ditulis tahun 1849 Masehi. Hasil penelitian menunjukkan, kitab yang populer dengan nama Salasilah Kutai ini sah dipergunakan sebagai sumber sejarah. Proses Islamisasi di Kerajaan Kutai Kertanegara berlangsung melalui peran seorang juru dakwah bernama Tuan Tunggang Parangan yang melakukan dialektika yang egaliter kepada Raja Makota pada tahun 1575.

Kata kunci : Islam, Islamisasi, Kerajaan Kutai Kertanegara, Salasilah Kutai 


\section{PENDAHULUAN}

Penulisan sejarah mengenai peristiwa masuknya Islam di Kerajaan Kutai Kertanegara masih minim yang berbasis sumber primer. Sejumlah tulisan yang ada, termasuk tugas akhir kesarjanaan dan artikel yang diterbitkan di jurnal akademik, menggunakan sumber sekunder dan karangan fiksi. Penulis dan peneliti tersebut umumnya merujuk buku teks Latin yang berjudul Salasilah Kutai. Padahal buku ini bukanlah transliterasi dari naskah aksara Arab Melayu Salasilah Kutai yang orisinal, melainkan gubahan beberapa cerita rakyat yang dikarang oleh penulis bernama samaran D. Adham alias Ahmad Dahlan. Hal ini diungkapkan sendiri oleh D. Adham dalam Bab Pendahuluan di bukunya tersebut (Adham, 1981: 11).

Selain itu, beredar juga cerita dongeng tentang tokoh-tokoh tertentu yang menyebarkan Islam di Kesultanan Kutai pada kawasan Samarinda Seberang. Kisahnya tergolong dongeng karena sama sekali tidak mempunyai sumber sejarah. Bahkan, ada dongeng yang anakronistis, seperti penyebutan seorang tokoh yang faktanya berdakwah pada abad ke-19 dan ia dikatakan sudah datang ke Kesultanan Kutai pada abad ke-17. Kisah ini termuat dalam sebuah buku berjudul Jaringan Pesantren (Bentuk, Konsistensi dan Implikasi) yang ditulis oleh Dr. Khojir, terbit 2016. Pada halaman 159 diceritakan bahwa Sayyid Abdurrahman Assegaf yang bergelar Pangeran Bendahara dinarasikan mendirikan masjid di Samarinda Seberang pada tahun 1881. Sementara tarikh kedatangannya di Kesultanan Kutai disebut pada tahun 1698. Garis waktu antara eksistensi dakwah tahun kedatangan memiliki selisih yang terlampau jauh yakni kurang lebih dua abad. Penulisan tahun 1698 ini bukan kekeliruan tik (typo) karena penulis buku memperkuatnya dengan kisah pernikahan antara Pangeran Bendahara dan adik dari seorang tokoh lain yang diklaim tiba di Samarinda Seberang pada 1668. Hanya eksistensi dakwah Pangeran Bendahara yang memiliki sumber sejarah, antara lain catatan Carl Bock (1882: 25), riset Solco Walle Tromp (1887: 188-189, dan riset S.C. Knappert (1905: 636).

Kerajaan Kutai Kertanegara yang berdiri pada tahun 1300 awalnya menganut Hindu. Namun, Hindu yang dianut bercorak lokal, tidak sama persis Hindu dari India. Contohnya, di Kutai Kertanegara terdapat kepercayaan satwa mitologis bernama lembu suwana (Thahir, 1849: 9). Contoh lain, jenazah Raja Kutai Kertanegara tidak dikremasi sebagaimana Hindu India, melainkan dimasukkan dalam tajau atau guci khusus. Kemudian pada abad ke-16 monarki yang berpusat di Kutai Lama ini berubah menjadi kerajaan Islam. Berikutnya, pada ke-18 istilah raja sebagai pemegang takhta diganti dengan sultan. Kesultanan Kutai mempunyai naskah klasik beraksara Arab Melayu sebagai sumber historiografi tradisional. Naskah itu bernama lengkap Surat Salasilah Raja dalam Negeri Kutai Kertanegara, yang selesai ditulis oleh Khatib Muhammad Thahir pada 30 Rabiul Awal 1265 Hijriah atau 24 Februari 1849. Manuskrip ini populer dengan nama ringkasnya, Salasilah Kutai, yang sering disebut dalam pustaka-pustaka tempo dulu. Satu dari ilmuwan yang meneliti Salasilah Kutai, yakni Constantinus Alting Mees, 
mengungkapkan tempat penyimpanan kitab fisik orisinal Salasilah Kutai adalah di Perpustakaan Negeri Berlin, Jerman (Mees, 1935: 110).

Penelitian ini bertujuan: (1) menganalisis validitas kitab aksara Arab Melayu Salasilah Kutai sebagai sumber historiografi tradisional dan (2) mendeskripsikan proses Islamisasi Kerajaan Kutai Kertanegara dari teks mitologis menjadi narasi historis. Kajian riset ini diharapkan berkontribusi bagi khazanah pengetahuan Sejarah Nasional Indonesia sekaligus meluruskan informasi sejarah lokal Kalimantan Timur yang selama ini sering tercampur dengan kisah khayal atau dongeng serta hoaks.

Penelitian ini menggunakan sumber primer kitab Salasilah Kutai beraksara Arab Melayu. Berkas digital kitab ini bisa diakses dari situs Perpustakaan Berlin-Jerman. Dalam rekonstruksi sejarah juga dirujuk referensi dan hasil riset yang bermutu sebagai karya historiografi. Literatur yang dijadikan rujukan adalah pustaka-pustaka yang mempunyai kedalaman analisis dari para ahli sejarah yang diterbitkan sejak zaman Kolonial Belanda, baik sumber primer maupun sekunder.

\section{METODE}

Penyusunan karya tulis ini menempuh metode penelitian sejarah sebagaimana standar ilmu sejarah. Pertama, heuristik, yaitu pengumpulan sumber sejarah. Penulis menghimpun pustaka, referensi, dan literatur klasik yang ditulis 1-2 abad silam, sebagian dari situs internet penyedia berkas digital, sebagian dari bantuan kolega.

Kedua, kritik sumber, yaitu melakukan verifikasi atau pengecekan atas sumber sejarah melalui kritik ekstern dan kritik intern. Sumber diverifikasi keaslian/keabsahan literaturnya dan juga derajat kredibilitas informasinya. Ketiga, interpretasi, yaitu penafsiran atau pemberian makna atas fakta dan sumber sejarah. Pada tahap ini, peristiwa sejarah dianalisis bagaimana prosesnya dan bagaimana memahami proses terjadinya sejarah tersebut.

Keempat, historiografi, yaitu penulisan sejarah dengan memuat tiga substansi yaitu pendahuluan, hasil penelitian, dan simpulan dengan pembahasan yang memiliki retorik dan bahasa yang mudah dipahami publik secara umum. Penulisan karya ini menggunakan metode deskripsi analitis sehingga karya tulis ini lebih dari sekadar narasi peristiwa masa silam. Ada penelusuran mendalam terhadap riwayat masa lampau.

\section{HASIL DAN PEMBAHASAN}

\section{Kedudukan Naskah Arab Melayu Salasilah Kutai sebagai Sumber Sejarah}

Kerajaan Kutai Kertanegara berdiri kali pertama tahun 1300 Masehi di Jaitan Layar, sebuah lokasi di hilir Sungai Mahakam yang kini dikenal dengan nama Desa Kutai Lama, Kecamatan Anggana, Kabupaten Kutai Kartanegara, Provinsi Kalimantan Timur. Kerajaan yang 
didirikan oleh Aji Batara Agung Dewa Sakti ini berbeda dengan kerajaan lain yang telanjur populer disebut Kerajaan Kutai yang berpredikat kerajaan Hindu pertama di Nusantara. Monarki Hindu tertua yang berpusat di Muara Kaman sejak abad ke-4 M itu nama sebenarnya bukan Kutai, melainkan Martapura. Ibu kota Kerajaan Kutai Kertanegara di Jaitan Layar kemudian dipindahkan ke Tepian Batu (masih di Kutai Lama) pada 1360, lalu ke PemaranganJembayan pada 1732, dan terakhir menetap di Tenggarong sejak 1782 hingga berakhirnya otoritas Kesultanan Kutai pada 1960 (Sarip, 2020: 56).

Ada manuskrip bernama Surat Salasilah Raja dalam Negeri Kutai Kertanegara alias Salasilah Kutai beraksara Arab Melayu yang selesai ditulis oleh Khatib Muhammad Thahir pada pertengahan abad ke-19. Kitab berisi 119 halaman teks ini merupakan sumber historiografi tradisional untuk sebuah kerajaan yang berdiri di hilir Sungai Mahakam pada tahun 1300 Masehi.

Sekurang-kurangnya terdapat tujuh salinan naskah Salasilah Kutai tulisan tangan tempo dulu. Peneliti yang mengetahui/menyaksikan salinan tersebut antara lain Solco Walle Tromp, Constantinus Alting Mees, W. Kern, Mohammad Asli Amin, dan Ahmad Dahlan. Kern (1956:1) mencatat ada lima salinan yang diketahuinya. Salinan pertama terdapat di Berlin, yang selesai ditulis oleh Khatib Muhammad Thahir pada 1849. Menurut peneliti Hikayat Banjar, Johanes Jacobus Ras (1990: 88), penulis Salasilah Kutai pada awal abad ke-19 adalah adalah seorang Banjar yang bekerja sebagai juru tulis Kesultanan Kutai Kertanegara. Salinan kedua terdapat di Leiden, yang selesai ditulis pada tahun 1868 oleh Encik Muhammad Tayib, dan kemudian ditransliterasi ke aksara Latin oleh S.W. Tromp. Salinan ketiga dikoleksi S.C. Knappert dari tulisan tangan Sultan Kutai tahun 1899. Salinan keempat terdapat di Batavia dalam aksara Latin (Kern, 1956: 1). Salinan kelima berupa naskah ringkas, ditulis oleh Awang Lambang dari Kampung Panji (Tenggarong), diperoleh Kern tahun 1941. Kemudian, M. Asli Amin menambahkan informasi satu salinan (keenam) yang dipegang Aji Demang Kedaton di Tenggarong..

\section{Tabel 1. Identifikasi Manuskrip Salasilah Kutai}

\begin{tabular}{ll}
\hline Koleksi & Perpustakaan Berlin-Jerman (naskah fisik asli) \\
\hline Judul & Surat Salasilah Raja dalam Negeri Kutai Kertanegara \\
\hline Penulis & Khatib Muhammad Thahir \\
\hline Pengantar & Tidak ada, langsung ke isi teks \\
\hline Penutup & $\begin{array}{l}\text { Keterangan tentang waktu dan tempat penyelesaian penulisan } \\
\text { naskah dan nama penulisnya }\end{array}$ \\
\hline Ukuran naskah & 34X 21 cm, total 132 halaman \\
\hline Jumlah halaman & Halaman teks: 119; halaman kosong: 13 \\
\hline
\end{tabular}




\begin{tabular}{ll}
\hline Ukuran area teks & 15 X $26 \mathrm{~cm}$ \\
\hline Isi & $\begin{array}{l}\text { Lengkap. Jumlah teks rata-rata 25 baris per halaman. Warna teks } \\
\text { hitam. Ada kata tertentu seperti nama tokoh, berwarna merah }\end{array}$ \\
\hline Jenis tulisan & Aksara Arab Melayu (Jawi), khat naskhi \\
\hline Bahasa & Melayu bercampur Kutai Kuno \\
\hline Waktu penyelesaian & 30 Rabiul Awal 1265 Hijriah (24 Februari 1849 Masehi) \\
penulisan & \\
\hline
\end{tabular}

Sumber: data diolah penulis (Sarip, 2020)

Dari sejumlah naskah Salasilah Kutai, terdapat buku ejaan Latin yang berjudul sama dengan Salasilah Kutai. Namun, isi buku ini bukanlah transliterasi orisinal dari kitab Salasilah Kutai Arab Melayu. Buku tersebut dikarang oleh D. Adham alias Ahmad Dahlan dan diterbitkan oleh Pemerintah Daerah Kabupaten Kutai dalam beberapa edisi sejak 1979. Dalam Kata Pengantarnya, Adham mengakui bahwa bukunya merupakan gubahan atas naskah Salasilah Kutai dengan dramatisasi cerita dan penambahan kisah dari sumber-sumber cerita rakyat lain. Salasilah Kutai versi Ahmad Dahlan ini memiliki kelemahan karena ia juga menyisipkan unsur rekayasa data. Contohnya, ada susunan 15 raja di Muara Kaman yang memerintah setelah Raja Mulawarman abad ke-5 hingga abad ke-14. Daftar nama-nama raja Martapura ini disisipkannya pada dialog antara Maharaja Indera Mulia dari Muara Kaman dengan Maharaja Sultan dari Kutai Lama (Adham, 1981: 100).

Beberapa peneliti dan arkeolog yang menyusun penelitian tentang kerajaan di Muara Kaman terkecoh dengan buku Latin Salasilah Kutai. Mereka menginterpretasikan sejarah Kutai bersandar pada narasi buku berjudul Salasilah Kutai. Tampaknya, mereka menyangka buku Salasilah Kutai adalah transliterasi dari kitab klasik beraksara Arab Melayu. Buku yang dirujuk pun cetakan terakhir (2002) yang juga mengalami penyimpangan setelah pengarangnya wafat pada tahun 1986. Sebagian orang juga bisa jadi terkecoh jika mengunduh berkas digital buku Salasilah Kutai terbitan 1981 dari situs internet Kemdikbud karena keterangan resensinya disebut sebagai "dokumen sejarah". Realitasnya, buku Latin Salasilah Kutai berbeda dengan kitab Arab Melayu Salasilah Kutai. Perbedaannya, buku Salasilah Kutai adalah buku cerita rakyat karangan D. Adham pada tahun 1981, sedangkan kitab Salasilah Kutai adalah manuskrip karya Khatib Muhammad Thahir tahun 1849.

Kitab Salasilah Kutai merupakan susastra Melayu yang ditulis pada pertengahan abad ke-19. Isinya mengandung kisah rasional dan cerita mitologi tentang silsilah raja-raja Kutai Kertanegara. Lantas, seberapa validkah susastra Salasilah Kutai dijadikan sumber sejarah? Apakah tulisan yang menceritakan kejadian masa silam dengan selisih ratusan tahun dari waktu penulisannya, dapat dipercaya sebagai sumber sejarah? 
Ilmuwan mengemukakan ciri umum karya tradisional Melayu bercorak sejarah sebagai berikut: (1) menceritakan asal-usul raja; (2) menceritakan keturunan raja-raja; (3) mengisahkan pembukaan sebuah negeri oleh seorang raja dan asal-usul penamaan negeri yang baru dibuka; (4) menceritakan bagaimana agama Islam berkembang di negeri bersangkutan, siapa tokoh yang berperan penting dalam penyebaran itu dan bagaimana kemudian Islam dipraktikkan dalam berbagai aspek kehidupan; dan (5) menceritakan keadaan negeri, peristiwa-peristiwa penting yang terjadi dari awal hingga masa paling akhir ketika buku itu ditulis (Abdullah, 2012: 215).

Naskah Salasilah Kutai serupa dengan kitab Nagarakretagama dan Pararaton, yakni sama-sama merupakan pujasastra. Salasilah Kutai hanya menyajikan aspek positif, superioritas, dan hegemoni dinasti Kerajaan Kutai Kertanegara. Dalam konteks ini, menurut Ong Hok Ham, karya historiografi tradisional di Nusantara seperti babad dan hikayat dipakai untuk tujuan legitimasi atau untuk menonjolkan tokoh sebagai teladan. Sejarah semacam ini ditulis dalam bahasa kebudayaan setempat dan bersifat kontemporer. Artinya, penggambaran istana masa lampau dilakukan dengan penceritaan yang dimengerti oleh penyimaknya pada masa itu. (Ong Hok Ham, 2018: 419-420). Dengan kata lain, sejarah dinasti raja yang penulisannya dilakukan pada masa lampau disesuaikan dengan daya pikir masyarakat yang berkembang pada zaman tersebut.

Sejarawan Slamet Muljana mengungkapkan, percampuran antara fakta sejarah dan mitologi yang dijalin dengan kepercayaan banyak terdapat dalam karya sastra lama, baik di Eropa maupun di Asia. Jika unsur-unsur mitologi dan kepercayaan itu ditanggalkan, yang tersisa ialah data-data sejarah. Unsur-unsur mitologi dan agama itu dimaksudkan sebagai ramuan guna mengolah fakta sejarah untuk menyatakan keistimewaan tokoh sejarah sesuai dengan alam pikiran pembacanya (Muljana, 1979: 71).

Kapasitas Salasilah Kutai sebagai pujasastra yang diliputi mitologis tidak serta-merta menihilkan fungsinya sebagai sumber sejarah. Pada masa penulisan Salasilah Kutai, masyarakat lokal belum mengenal pendidikan modern yang mengutamakan rasionalisme. Maka, konten riwayat masa lalu sebagaimana hikayat Melayu lainnya adalah relevan dengan masyarakat pada zamannya. Unsur mitos, mistik, dongeng, dan irasional yang disajikan dalam Salasilah Kutai mesti diinterpretasikan secara logis dan rasional. Informasi yang 'wajar' pun mesti dikomparasikan dengan sumber lain. Hal ini agar naskah kuno tersebut tetap relevan dengan zaman modern. Dengan demikian, ia akan menjadi sumber ilmiah bagi penelitian sejarah.

Pada intinya, penulisan naskah susastra Melayu atau babad di Jawa cenderung mengikuti subjektivitas penguasa. Meskipun begitu, Wang Gung Wu, ahli sejarah Asia Tenggara, berpendapat bahwa terhadap kronik-kronik atau karya tulis sejarah tradisional, kalangan ilmiah masa kini sudah mulai menghargainya. Menurutnya, terlepas dari persoalan apakah 
karya-karya tersebut dapat dinamakan "sejarah" atau tidak, nilainya sebagai suatu dokumen sejarah telah terbukti sekarang. Yang diperlukan kini adalah teknik-teknik yang lebih halus dan lebih peka untuk mendapatkan data-data yang diperlukan untuk menulis sejarah (Abdullah, 2016: 9).

Snouck Hurgronje, seorang pakar kebudayaan Melayu dan Islam, intens meneliti pada penghujung abad ke-19 dan awal abad ke-20. Ia turut mengkaji manuskrip Salasilah Kutai pada 1888. Menurut Hurgronje, orang-orang pada masa kuno tidak mempunyai banyak cara ketika memulai pencatatan tradisi sejarahnya. Para raja dan keluarga terkemuka menginginkan suatu dokumen yang mengesahkan turunan kebangsawanan serta kejayaan gemilang yang telah dilakukan oleh nenek moyang mereka. Mereka juga ingin mendokumentasikan hubungan kerajaan mereka dengan kerajaan-kerajaan lain. Lantas, karena imajinasi mereka tidak dibatasi oleh kualifikasi yang amat ketat ketika membuat dokumentasi seperti itu, maka segala macam mitos digunakan untuk mengagungkan dinasti mereka. Karenanya menurut Hurgronje, nenek moyang raja atau pendiri dinasti dideskripsikan dengan kuasa dan keagungan. Sementara saingan-saingan dan kerajaan-kerajaan yang setara dinarasikan sebagai bekas jajahan. Kemudian, Islamisasi kerajaan dilakukan oleh para ulama yang mempunyai kuasa-kuasa gaib, jika tidak dilakukan oleh nabi sendiri. Sekiranya kita menerima mitos-mitos dan legendalegenda ini dalam keadaan sebenarnya, kita dapati bahwa hal tersebut menjadi sumber pengetahuan yang berharga (Hurgronje, 1888: 109-110).

Masih menurut Hurgronje, semua tradisi penulisan lama yang populer ini mengandung maklumat yang kaya tentang undang-undang dan institusi-institusi yang dihormati. Ceritacerita yang bukan bersifat sejarah tentang asal usul mereka pun menjadi amat berguna bagi orang yang tahu menggunakannya. Cerita-cerita ini baik dari segi bentuk maupun isi, merupakan di antara yang paling asli dan menggambarkan sifat kesusastraan prosa setiap bangsa di India Timur (Hurgronje, 1888: 110).

Historiografi lokal seperti hikayat, babad, silsilah, salasilah, tambo, dan sejenisnya tidak bisa dieliminasi dalam penulisan sejarah. Jan Vansina (1965) sebagaimana dinukil Prof. Azyumardi Azra menyatakan bahwa historiografi lokal tak bisa diabaikan karena mengandung "pesan substantif" dalam mentalitas yang berlangsung dalam masa panjang. Awalnya, historiografi ini didasari fakta historis yang disampaikan secara lisan turun-temurun yang dalam perjalanan sejarah antargenerasi bertambah dengan mitos dan legenda. Karena itu, orang tidak boleh mengambil historiografi lokal itu secara face-value, tapi sebaliknya, menukik ke dalam mentalitasnya (Azra, 2020).

Pada masa mutakhir, ada pendapat dari Prof. Abdul Hadi, Guru Besar Filsafat Islam Universitas Paramadina Jakarta, yang mengklasifikasikan Salasilah Kutai sebagai sastra sejarah (Hadi dalam Abdullah, 2012: 215). Pernyataan ini termuat dalam buku Indonesia dalam Arus 
Sejarah Jilid 3: Kedatangan dan Peradaban Islam. Dalam buku terbitan 2012 tersebut, Abdul Hadi menulis bab yang berjudul "Tradisi Sastra dan Kebahasaan". Dengan demikian, berdasarkan sejumlah analisis dan pendapat para ilmuwan dan sejarawan, Salasilah Kutai sah dikategorikan sebagai sumber sejarah.

\section{Peran Wali Pengembara dalam Islamisasi di Kerajaan Kutai Kertanegara}

Sejak akhir abad ke-13 Masehi sampai tiga perempat abad ke-16, Kerajaan Kutai Kertanegara masih menganut agama Hindu corak lokal. Informasi tentang adanya agama baru, yakni Islam, yang dianut penduduk negeri lainnya di Pulau Kalimantan, boleh jadi telah diketahui oleh Raja Makota (1525-1600). Hal ini mengingat pada awal abad ke-16 Kerajaan Banjar sudah menjadi kesultanan Islam. Dalam kaitan ini, Kutai Kertanegara merupakan vasal dari Kesultanan Banjar yang berkewajiban memberi upeti kepada Sultan Banjar (Ras, 1990: 270).

Jauh sebelum itu, pada abad ke-14 dan 15, pengaruh Islam sudah masuk ke Kutai Kertanegara melalui jalur perdagangan oleh pedagang muslim dari kerajaan-kerajaan Islam yang mulai berdiri di Pulau Jawa, Sumatra, dan Melayu. Hal ini tampak dari pemberian nama Maharaja Sultan (1360-1420), putra kelima Aji Batara Agung Paduka Nira. Nama Sultan berasal dari istilah pemimpin dalam negeri-negeri Islam. Demikian pula, nama Raja Mandarsyah (14201475), akhiran syah memperlihatkan kemiripan dengan gelar raja-raja muslim di Persia dan raja muslim di Samudra Pasai. Namun, meskipun Islam telah berpengaruh pada nama raja, agama Islam belum dianut Raja Kutai kala itu (Amin, 1975: 31).

Menurut analisis ahli susastra Melayu, Constantinus Alting Mees, tarikh masuk Islamnya Raja Kutai Kertanegara terjadi pada tahun 1575 (Mees, 1935: 54). Kala itu seorang mubalig atau juru dakwah Islam tiba di Tepian Batu, Kutai Lama. Rakyat Kutai Kertanegara menyambutnya dengan sikap terbuka dan tanpa penolakan. Padahal sang mubalig yang dijuluki Tuan Tunggang Parangan itu membawa misi religius yang berbeda dengan ajaran yang sudah lama dianut masyarakat setempat.

Sebenarnya ulama yang datang berperahu memasuki Sungai Mahakam itu ada dua orang. Satunya adalah Tuan Di Bandang. Mereka berdua berangkat dari Makassar. Namun, keduanya bukan orang Makassar, melainkan Minangkabau. Mereka berlayar ke Kutai setelah mengislamkan penduduk Makassar. Setibanya di Kutai, mereka mendapat kabar bahwa sebagian penduduk Makassar yang baru masuk Islam atau mualaf kembali ke kepercayaan asalnya alias murtad. Tuan Di Bandang yang dikenal pula dengan nama Datuk Ri Bandang, segera kembali ke Makassar untuk tugas dakwah. Tuan Di Bandang belum sempat bertemu dengan pemilik singgasana Kutai kala itu, Raja Makota (Thahir, 1849: 98). Sementara itu, pengarang buku teks Latin Salasilah Kutai mengubah substansi riwayat dari aspek tokoh 
dengan menceritakan bahwa Tuan Di Bandang tetap bersama Tunggang Parangan bertemu Raja Kutai (Adham, 1981: 225-226).

Tuan Tunggang Parangan sendirian menemui Raja Makota. Mengenai nama Tunggang Parangan, ini merupakan gelar yang diberikan pihak Kutai. Salasilah Kutai menceritakan hikayat mubalig tersebut menunggangi ikan parangan di Sungai Mahakam ketika tiba di Kutai. Lantas, Constantinus Alting Mees menafsirkan kisah ini sebagai kiasan bahwa sang ulama menaiki sebuah perahu yang ujungnya lancip seperti moncong ikan parangan (Mees, 1935: 54).

Ada sebuah pustaka yang menyebutkan nama asli Tunggang Parangan, yaitu Said Muhammad bin Abdullah bin Abu Bakar Al Warsak. Namun, buku penyebutannya di buku berjudul Sejarah Daerah Kalimantan Timur ini tidak disertai dengan keterangan sumber primernya (Wirakusumah, 1978: 32-33). Nama berbeda juga tertera di pelang nama kompleks makam Tunggang Parangan di Desa Kutai Lama. Di atas bangunan makam tertulis nama Habib Hasim bin Musaiyah. Penulisan kedua nama ini belum diketahui akurasinya. Belum ditemukan sumber yang sahih mengenai nama asli dari Tunggang Parangan.

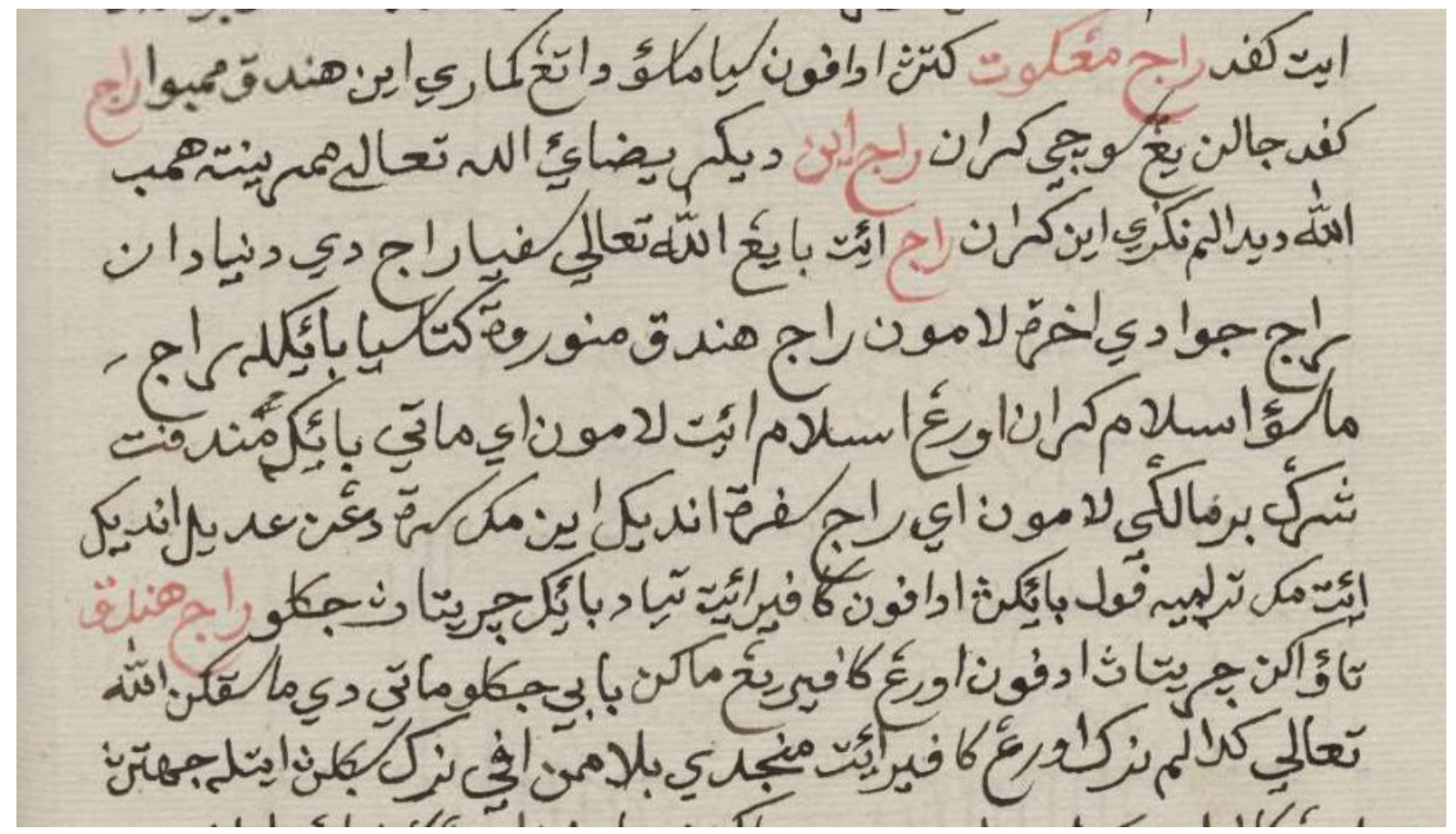

Gambar 1. Kutipan teks Arab Melayu Salasilah Kutai halaman 99 tentang kalimat ajakan berislam oleh Tunggang Parangan kepada Raja Makota

Sumber: Surat Salasilah Raja dalam Negeri Kutai Kertanegara, 1849.

Kemudian, Salasilah Kutai mendeskripsikan proses masuk Islamnya Raja Makota didahului dengan ajakan berislam oleh Tuan Tunggang Parangan. Teks kalimat awal Tunggang Parangan ini terdapat pada halaman ke-99 sebagaimana transliterasi berikut ini.

"Adapun saya masuk datang ke mari ini hendak membawa raja kepada jalan yang suci, karena raja ini, dikeridhai Allah Ta'ala memerintah hamba Allah di dalam negeri ini, karena raja itu bayang-bayang Allah Ta'ala supaya raja di dunia, dan 
raja di akhirat. Lamun raja hendak menurut saya, baiklah, raja masuk Islam karena orang Islam itu lamun ia mati baik mendapat surga berapa lagi, lamun ia raja seperti andika ini maka serta dengan adil andika itu maka terlebih baik pula. Adapun kafir itu tiada baik ceritanya. Jikalau raja hendak tahu, akan ceritanya, adapun orang kafir yang makan babi, jikalau mati dimasukkan Allah Ta'ala ke dalam neraka orang kafir itu."

Pada bagian berikutnya Salasilah Kutai diterangkan bahwa Raja Makota tidak serta merta menerima ajakan Tunggang Parangan. Ia ingin menguji kesaktian mubalig tersebut. Pertama, Raja Makota menghilang dan meminta ditunjukkan tempat berdirinya. Tunggang Parangan berhasil menunjukkannya. Kedua, Raja Makota mengajak Tunggang Parangan beranjak ke lokasi yang jauh dari ibu kota kerajaan didiringi rakyat, lalu dengan kesaktiannya membuat api yang sangat besar. Raja meminta Tunggang Parangan memadamkan kobaran api itu. Tunggang Parangan berwudu kemudian melakukan salat dua rakaat. Selanjutnya, turunlah hujan lebat yang memadamkan api tersebut. Namun, hujan makin deras dan menenggelamkan daerah Kutai. Tunggang Parangan pun memanggil ikan parangan dan berkata, "Hai, Jukut, barang siapa tiada mau mendengar kataku, engkaulah yang punya bagian." Khawatir akan kehancuran kerajaan dan kebinasaan rakyatnya, Raja Makota menyatakan kesediaan memeluk Islam (Thahir, 99100).

Kisah adu kesaktian antara Raja Makota dengan Tuan Tunggang Parangan secara harfiah serupa dengan riwayat metode dakwah yang menonjolkan narasi karamah, mukjizat atau keajaiban. Meskipun begitu, cerita tekstual tersebut dapat diinterpretasikan sebagai cara dakwah yang terjadi melalui dialog secara egaliter. Adu kesaktian itu juga bermakna perdebatan nalar atau dialektika yang akhirnya dimenangkan Tunggang Parangan, sehingga Raja Makota sukarela berislam (Sarip: 2018: 77). Dakwah Tunggang Parangan kepada Raja Makota tidak melalui jalan kekerasan. Sikap moderat atau pertengahan dan memaklumi uzur diberikan kepada Raja Makota ketika ia meminta penangguhan waktu sebelum resmi masuk Islam. Raja ingin mengonsumsi daging babi dari ternak yang ada di istananya serta pekasam atau daging asinan babi yang tersisa di tempayan. Sebabnya, setelah menjadi muslim, konsumsi babi adalah perbuatan terlarang.

Skema Islamisasi di tanah Kutai ini sesuai dengan analisis Azra mengenai proses Islamisasi di tempat tertentu di Kepulauan Nusantara. Pada umumnya proses Islamisasi bermula dari kedatangan "guru pengembara" asal Arab dengan nama khas Arab, yang sering disebut syekh atau habib. Secara tipikal, lanjut Azra, guru pengembara itu adalah syekh sufi atau "wali". Guru pengembara sufi sekaligus wali ini mengajak penguasa lokal untuk masuk Islam dan sering melalui pertarungan kekuatan gaib. Para guru pengembara ini, sebagaimana karakter sufisme atau tasawuf, bersikap inklusif dan akomodatif (Azra: 2020). 
Selama menanti masa penangguhan, Tunggang Parangan minta dibangunkan langgar atau surau. Usai daging babi habis, Tunggang Parangan memandu Raja Makota mengikrarkan kalimat syahadat sebagai ritual resmi masuk Islam. Raja pun diajarkan tata cara salat. Tunggang Parangan juga menggelar kajian agama, mengajarkan Rukun Islam, Rukun Iman, dan bacaan doa-doa serta dzikir. Segenap keluarga dan punggawa istana serta rakyat Kutai Kertanegara turut menjadi muslim.

Sistem religi masyarakat Kutai Kertanegara berganti menjadi sistem Islam mulai akhir abad ke-16. Dalam Islam, kedudukan sosial setiap individu adalah egaliter/sederajat, tidak dibedakan secara kasta. Namun, status sosial yang istimewa tetap ada untuk golongan orang yang ahli agama, seperti imam masjid, guru agama, dan penghulu (Sarip, 2018: 77). Kemudian, Raja bersama Tunggang Parangan melakukan Islamisasi ke perkampungan Samarinda hingga ke pesisir utara di Kalimantan bagian timur. Salasilah Kutai mencatat daerah yang diislamkan itu yaitu Luah Bakung (bagian barat Samarinda), Kaniungan, Manubar Sangkulirang, dan Balikpapan (Mees, 1935: 244).

Masjid pertama di Kutai Kertanegara dibangun ketika putra mahkota dari Raja Makota yang bernama Aji Dilanggar berusia 14 tahun. Hal ini terjadi pada penghujung abad ke-16 atau sekitar tahun 1600. Tuan Tunggang Parangan termasuk yang mengawasi proyek pembangunan masjid dari aspek arsitektur dan aksesoris serta ukiran di dalamnya (Mees, 1935: 246-247). Tentu saja masjid ini tidak atau belum ditemukan tinggalan arkeologinya pada abad ke-21 karena bahan material dari kayu sudah lazim mengalami pelapukan, kalau tidak dibongkar sama sekali untuk diganti yang baru atau dipindah ke lokasi lain.

Penerimaan Islam oleh Raja Kutai Kertanegara tampaknya selaras dengan analisis Carool Kersten. Penguasa berbasis perdagangan di muara-muara sungai kawasan Asia Tenggara, menurut Kersten, mempunyai motif kemasyarakatan. Islam menawarkan satu cara pemersatu menghadapi tantangan yang diberikan kerajaan-kerajaan berbasis sawah di Asia Tenggara daratan. Aspek Islam sebagai agama kemasyarakatan juga tampak di pentingnya ibadah seperti salat, zakat, dan puasa (Kersten, 2018: 43).

Raja Makota bersama Tunggang Parangan kemudian melakukan Islamisasi ke daerah sekitar ibu kota Kutai. Namun, pengislaman hanya menjangkau pesisir timur Kalimantan. Perjalanan dakwah dari Kutai Lama ke arah selatan sampai Balikpapan. Adapun ke utara, safari hingga Sangkulirang (Mees, 1935: 101).

Dogma Islam yang dianut entitas Kutai Kertanegara bersifat sinkretis atau berpadu dengan kepercayaan dan kebudayaan tradisional lokal. Contohnya, upacara adat erau tetap dipertahankan dengan menambahkan bacaan mantra dari ayat-ayat Alquran dan doa-doa Islami. Bentuk masjid atau langgar sebagai rumah ibadah muslim juga tidak sama dengan arsitektur masjid di Jazirah Arab. Ada kekhasan dalam pembangunan masjid di Kutai Kertanegara, 
sebagaimana bangunan surau bangsa Melayu yang berbahan dasar dari kayu. Penempatan masjid di umumnya di bantaran Sungai Mahakam karena faktor kedekatan dengan sumber air. Hal ini mengingat tata cara ibadah muslim dimulai dengan wudu yakni proses penyucian diri menggunakan air (Sarip, 2017: 48).

\section{KESIMPULAN}

Manuskrip klasik beraksara Arab Melayu Surat Salasilah Raja dalam Negeri Kutai Kertanegara termasuk sumber historiografi tradisional. Judul kitab ini diperoleh dari bagian akhir tulisan Khatib Muhammad Thahir yang menyebutkan nama naskahnya. Penamaan kitab kemudian diringkas dan dipopulerkan oleh para ilmuwan dengan nama Salasilah Kutai. Dengan verifikasi yang ketat, meliputi kritik ekstern dan intern, Salasilah Kutai yang selesai ditulis tahun 1849 valid digunakan sebagai sumber sejarah. Namun, publik perlu memerhatikan bahwa Salasilah Kutai yang dimaksud bukanlah buku-buku teks Latin berjudul Salasilah Kutai yang diterbitkan pada era 1980-an.

Proses masuk Islamnya Raja Kutai Kertanegara ke-6 pada 1575 terjadi melalui peran guru atau wali pengembara secara damai tanpa kekerasan. Tunggang Parangan menjadi tokoh sufi juru dakwah utama penyebaran Islam di Kerajaan Kutai Kertanegara. Adapun tokoh Datuk Ri Bandang urung berdakwah di timur Kalimantan karena fokus berdakwah di Makassar. Islamisasi di Kutai Kertanegara berlangsung melalui dialektika yang egaliter antara Tuan Tunggang Parangan dan Raja Makota.

Setelah di ibu kota kerajaan di Kutai Lama, pengislaman yang dilakukan Tunggang Parangan atas seizin Raja Makota terjadi di sepanjang pesisir timur Kalimantan sampai ke Sangkulirang di bagian utara dan Balikpapan di bagian selatan. Dogma Islam yang didakwahkan dapat beradaptasi dengan masyarakat Kutai karena tidak menghapuskan tradisi dan adat istiadat lama

\section{REFERENSI}

Abdullah, Taufik \& A.B. Lapian (Ed.) (2012). Indonesia dalam Arus Sejarah Jilid 3: Kedatangan dan Peradaban Islam. Jakarta: Ichtiar Baru van Hoeve.

Adham, D. (1981). Salasilah Kutai. Jakarta: Departemen Pendidikan dan Kebudayaan.

Ahyat, Ita Syamtasiyah. (2013). Kesultanan Kutai 1825-1910: Perubahan Politik dan Ekonomi Akibat Penetrasi Kekuasaan Belanda. Tangerang Selatan: Serat Alam Media, 2013.

Amin, M. Asli, dkk. (1975). Dari Swapraja ke Kabupaten Kutai. Tenggarong: Pemerintah Daerah Kabupaten Kutai Kalimantan Timur.

Azra, Azyumardi. (2020). "Wali, Islamisasi, dan Unifikasi Nusantara”. Tempo No. 14, 25-31 Mei 2020. 
Bock, Carl. (1882). The Head-Hunters of Borneo: A Narrative of Travel up the Mahakkam and Down the Barito; also, Journeyings in Sumatra. London: Sampson Low, Marston, Searle, \& Rivington.

Hurgronje, Snouck. (1888). "Nog Iets Over de Salasila van Koetei.” Bijdragen tot de Taal-, Landen Volkenkunde van Nederlandsch-Indië, Deel 37. 109-120.

Kern, W. (1956). Commentaar op de Salasilah van Koetai. ‘s-Gravenhage: Martinus Nijhoff.

Kersten, Carool. (2018). Mengislamkan Indonesia: Sejarah Peradaban Islam di Nusantara, terjemahan dari A History of Islam in Indonesia terbitan Edinburgh University Press, 2017. Tangerang Selatan: Penerbit Baca.

Knappert, S.C. (1905). “Beschrijving Van De Onderafdeeling Koetei.” Bijdragen tot de taal-, landen volkenkunde, Volume 58, Issue 1. 575-654.

Mees, Constantinus Alting. (1935). De Kroniek van Koetai Tekstuitgave Met Toelichting. Santpoort: N.V. Uitgeverij.

Muljana, Slamet. (2006). Tafsir Sejarah Nagara Kretagama. Diterbitkan pertama kali oleh Bhatara Karya Aksara, 1979. Yogyakarta: LkiS.

Ong Hok Ham. (2018). Wahyu yang Hilang Negeri yang Guncang. Jakarta: Kepustakaan Populer Gramedia.

Ras, Johannes Jacobus. (1990). Hikayat Banjar. Diterjemahkan oleh Siti Hawa Salleh. Kuala Lumpur: Dewan Bahasa dan Pustaka.

Sarip, Muhammad. (2017). Samarinda Tempo Doeloe: Sejarah Lokal 1200-1999. Samarinda: RV Pustaka Horizon.

Sarip, Muhammad. (2018). Dari Jaitan Layar sampai Tepian Pandan Sejarah Tujuh Abad Kerajaan Kutai Kertanegara. Samarinda: RV Pustaka Horizon.

Sarip, Muhammad. (2020). "Kajian Etimologis Kerajaan (Kutai) Martapura di Muara Kaman, Kalimantan Timur". Yupa: Historical Studies Journal, 4(2), 50-61. https://doi.org/10.30872/yupa.v4i2.264.

Thahir, Khatib Muhammad. (1849). Surat Salasilah Raja dalam Negeri Kutai Kertanegara. (Aksara Arab Melayu). http://resolver.staatsbibliothek-berlin.de/SBB00019D9A0000 0000. Diakses 30 Juli 2019.

Tromp, S.W. (1888). Uit de Salasila Van Koetei. 's-Gravenhage: Martinus Nijhoff.

Wirakusumah, Sambas dkk. (1978). Sejarah Daerah Kalimantan Timur. Jakarta: Departemen Pendidikan dan Kebudayaan Proyek Inventarisasi dan Dokumentasi Kebudayaan Daerah 1976/1977. 